\title{
Erratum to: Autism Spectrum Disorder Screening Refusal Rates: Findings from a Statewide Early Intervention Program
}

\author{
Maya Matheis $^{1} \cdot$ Johnny L. Matson ${ }^{1}$
}

Published online: 2 October 2015

(C) Springer Science+Business Media New York 2015

\section{Erratum to: J Dev Phys Disabil \\ DOI 10.1007/s10882-015-9449-x}

In the original published version of this article, information pertaining to ethical approval, informed consent, and potential conflicts of interest were not noted. The authors have included this information below. This error has no implications for the analysis or reported results.

\section{Ethical approval:}

The Louisiana State University Institutional Review Board and the State of Louisiana's Department of Health and Hospitals Institutional Review Board have approved the use of data from EarlySteps for research purposes. All procedures were in accordance with the ethical standards of the institutional and/or national research committee and with the 1964 Helsinki declaration and its later amendments or comparable ethical standards.

\section{Informed consent:}

Informed consent was obtained from all informants, who were parents or legal guardians of the participating children.

\section{Disclosure of potential conflicts of interest:}

Deann Matson, Dr. Johnny Matson's wife, is the sole owner of the Baby and Infant Screen for Children with autism Traits (BISCUIT) and sells the scale.

The online version of the original article can be found at http://dx.doi.org/10.1007/s10882-015-9449-x.

Maya Matheis

maya.matheis@gmail.com

1 Department of Psychology, Louisiana State University, 236 Audubon Hall, Baton Rouge, LA 70803, USA 